\title{
Vulvar Yolk Sac Tumor
}

National Cancer Institute

\section{Source}

National Cancer Institute. Vulvar Yolk Sac Tumor. NCI Thesaurus. Code C128295.

A rare yolk sac tumor that arises from the vulva. 